\title{
Viabilidade do sêmen congelado obtido do epidídimo de touros post-mortem
}

\section{Viability of frozen semen obtained from epididymis of bulls post-mortem}

\author{
Luciano Munita Barbosa, ${ }^{*}$ Mábilis Yumi Kanazawa, ${ }^{* *}$ Anelise Ribeiro Peres, ${ }^{* \star *}$ Fabiana Ferreira de Souza ${ }^{* \star * *}$
}

\begin{abstract}
Resumo
O objetivo deste estudo foi avaliar os efeitos da congelação sobre a integridade e funcionalidade de espermatozoides colhidos do epidídimo de touros post-mortem. Foram utilizados 10 pares de testículos de touros provenientes de um abatedouro comercial. No laboratório, o sêmen foi colhido da cauda do epidídimo sobre uma placa de Petri aquecida, contendo meio diluente sem glicerol (Botubov ${ }^{\circledR}$ - meio I, Botupharma, Botucatu, SP). O sêmen foi então avaliado quanto à motilidade, vigor, concentração, morfologia espermática, integridade de DNA, atividade mitocondrial, viabilidade, integridade e funcionalidade da membrana. Após a avaliação, o sêmen foi diluído em meio comercial contendo glicerol (Botubov ${ }^{\circledR}$ - meio II, Botupharma, Botucatu, SP), em uma concentração de $100 \times 10^{6}$ de espermatozoides $/ \mathrm{mL}$. Ato contínuo, as amostras foram envasadas em palhetas de $0,5 \mathrm{~mL}$, refrigeradas a $4^{\circ} \mathrm{C}$, durante 4 horas, congeladas em caixa de poliestireno expandido, a $6 \mathrm{~cm}$ do nível de nitrogênio líquido, durante 20 minutos e, posteriormente, armazenada em botijão criogênico. As amostras foram descongeladas a $37^{\circ} \mathrm{C}$, durante 30 segundos. Após a descongelação, o sêmen foi reavaliado para os mesmos parâmetros, com exceção da concentração espermática e volume. Quanto à comparação dos resultados entre o sêmen fresco e congelado, estes foram superiores $(p<0,05)$ no sêmen fresco quanto à motilidade $(74,0 \pm 7,0 \%$ versus $30,0 \pm 8,2 \%$ ), vigor $(3,6 \pm 0,7$ versus $1,3 \pm 0,5)$, integridade de membrana (fluorescência, $95,6 \pm$ $3,1 \%$ versus $75,7 \pm 5,9 \%$ ) e índice de atividade citoquímica mitocondrial $(99,3 \pm 6,6$ versus $40,0 \pm 6,3)$, respectivamente. Concluiuse que a viabilidade do sêmen congelado obtido do epidídimo de touros é semelhante à do sêmen ejaculado, tornando a técnica de colheita aplicável comercialmente.
\end{abstract}

Palavras-chave: criopreservação; ejaculado; bovino; espermatozoide; epididimal.

\begin{abstract}
The objective of this study was to evaluate the effects of freezing on the integrity and functionality of bovine epididymal spermatozoa collected postmortem. Ten pairs of testicle epididymis of bulls from a commercial slaughterhouse were used. On the laboratory, the testicle was separated and the semen was collected from the tail of epididymis on a petri dish heated containing a medium (Botubov ${ }^{\circledR}$, Botupharma, Botucatu, SP). Then, the semen was evaluated to motility, vigor, concentration, morphology, DNA integrity, mitochondrial activity, viability, membrane integrity and functionality. The semen was diluted in commercial extender (Botubov ( ), Botupharma, Botucatu, SP) at a concentration of $100 \times 10^{6} \mathrm{sperm} / \mathrm{mL}$. Thereafter, the samples were packaged in straws 0.5 $\mathrm{mL}$, chilled at $4^{\circ} \mathrm{C}$, for 4 hours, frozen in polystyrene box, at $6 \mathrm{~cm}$ from level of liquid nitrogen, during 20 minutes and stored in cryogenic container. The samples were thawed at $37^{\circ} \mathrm{C}$ for 30 seconds. After thawing, the semen was reevaluated to the same parameters, except sperm concentration and volume. Comparison of results between fresh and frozen semen showed means were increased $(p<0.05)$ fresh semen motility $(74,0 \pm 7,0 \%$ versus $30,0 \pm 8,2 \%)$, vigor $(3,6 \pm 0,7$ versus $1,3 \pm 0,5)$, membrane integrity (fluorescence, $95,6 \pm 3,1 \%$ versus $75,7 \pm 5,9 \%$ ) and index of mitochondrial activity $(99,3 \pm 6,6$ versus $40,0 \pm 6,3)$, respectively. In conclusion, the viability of frozen semen obtained from the epididymis of bulls is similar than ejaculated semen, making the collection technique commercially applicable.
\end{abstract}

Keywords: Criopreserved; Ejaculated; Bovine; Sperm; Epididymal.

\section{Introdução}

A cauda do epidídimo funciona como proteção e armazenamento dos espermatozoides até a ejaculação (Hinton et al.,1995). No touro, a cauda do epidídimo possui a capacidade de armazenar o equivalente a dez ejaculados sucessivos e devido a sua baixa atividade metabólica, os espermatozoides podem sobreviver por até 15 dias, enquanto que após a ejaculação sobrevivem por pouco mais que 24 horas (Bedford, 1994).

\footnotetext{
* Discente do curso de Graduação em Medicina Veterinária da Universidade de Franca, UNIFRAN, Franca, SP, Brasil.

** Médica Veterinária Autônoma, M. Cassab Foods, Rifaína, SP, Brasil.

*** Mestranda do Programa de Pós-graduação em Medicina Veterinária, Departamento de Medicina Veterinária Preventiva e Reprodução Animal, FCAV, UNESP, Jaboticabal, SP, Brasil.

**** Docente do Programa de Mestrado em Medicina Veterinária de Pequenos Animais e do Curso de Graduação em Medicina Veterinária, Universidade de Franca, UNIFRAN, Franca, SP, Brasil. Autor pra correspondência: E-mail: fafesouza@unifran.br.
} 
Os espermatozoides armazenados no epidídimo possuem a capacidade de fecundar o oócito, entretanto, o plasma seminal possui fatores decapacitantes, o que promovem alterações metabólicas e bioquímicas em sua estrutura, contribuindo com a capacitação e reação do acrossomo (Yang et al., 1993; Yanagimachi, 1994).

Apesar disto, Amann et al. (1974) mostraram que espermatozoides da cauda do epidídimo possuem capacidade fertilizante similar ao do ejaculado.

A colheita e a criopreservação dos espermatozoides da cauda do epidídimo podem ser a última chance e opção para preservação de células germinativas de animais de alto valor genético, reprodutores de idade avançada ou após a morte do animal.

Em vista do potencial de crescimento da inseminação artificial no Brasil (ASBIA, 2012), da chance de aproveitar o sêmen de reprodutores que morreram inesperadamente e da escassez de estudos quanto à qualidade do sêmen criopreservado colhido do epidídimo, o objetivo deste estudo foi avaliar a motilidade, vigor, concentração, morfologia espermática, integridade de DNA, integridade estrutural e funcional da membrana plasmática, viabilidade espermática e atividade mitocondrial, antes e após a congelação do sêmen obtido do epidídimo de touros post-mortem.

\section{Material e métodos}

O estudo foi realizado de acordo com preceitos éticos recomendados pelo Colégio Brasileiro de Experimentação Animal (COBEA), após aprovação pelo Comitê de Ética no Uso de Animais (CEUA), sob protocolo nº 013/11.

\section{Colheita e preparo do material}

Foram utilizados 10 pares de epidídimos (20 epidídimos) de touros, colhidos em um abatedouro comercial, durante o período de maio a dezembro de 2011. Os testículos/ epidídimos receberam uma ligadura com fio de náilon $(0,50$ $\mathrm{mm}$ ) no funículo espermático e foram acomodados em sacos plásticos, armazenados em caixa térmica e encaminhados até o Laboratório de Reprodução Animal.

No laboratório, as peças foram retiradas da caixa térmica, em seguida a cauda do epidídimo foi separada do tecido adjacente por dissecação e a colheita dos espermatozoides foi realizada pela técnica de fluxo retrógrado relatada por Garde et al. (1994) e Bruemmer et al. (2002). Nesta técnica, o ducto deferente é lavado com o uso de seringa e cateter, injetando-se $5 \mathrm{~mL}$ de diluente à base de TRIS-gema de ovo, sem crioprotetor (Botubov ${ }^{\circledR}$ - Meio I, Botupharma, Botucatu, SP) fazendo com que os espermatozoides sejam carreados pelo diluente, extravasando pela incisão realizada na junção entre a cauda e o corpo do epidídimo. Todo procedimento foi realizado sobre uma placa aquecedora.

Após a colheita, o sêmen foi analisado quanto à motilidade, vigor, concentração, morfologia espermática (método Karras), integridade de DNA (acridina laranja), integridade estrutural (diacetato de 6-carboxifluoresceína e iodeto de propídeo) e funcional da membrana plasmática (teste hiposmótico), viabilidade espermática (coloração com eosina/nigrosina) e atividade mitocondrial.

\section{Avaliação da motilidade e vigor}

Para avaliação da motilidade e vigor, uma alíquota de sêmen foi depositada sobre uma lâmina aquecida, recoberta por lamínula e observada em microscópio de contraste de fase, num aumento de 100X. A motilidade foi caracterizada pela presença de movimentos retilíneos e expressa em porcentagem ( 0 a $100 \%$ ). O vigor foi caracterizado de acordo com a intensidade dos movimentos espermáticos e expresso segundo um escore de 0 a 5.

\section{Avaliação da concentração espermática}

A concentração espermática foi avaliada após a diluição de 1:100 do sêmen em formol-salina. O sêmen diluído foi colocado na câmara de Neubauer e as células contadas em microscópio de contraste de fase, num aumento de 400X. O valor obtido foi dado em milhões $/ \mathrm{mL}$.

\section{Avaliação da morfologia espermática}

A morfologia espermática foi realizada utilizando-se o método Karras modificado (Papa et al., 1986). Uma alíquota de sêmen foi depositada na extremidade de uma lâmina fosca e um esfregaço foi confeccionado. A lâmina foi fixada em metanol (1 passagem) e corada pelo método citado. Foram contadas 200 células, classificadas de acordo com os tipos de defeitos (maiores, menores ou normais), num aumento de 1.000X em microscópio de contraste de fase. Os valores foram dados em porcentagem.

\section{Integridade do DNA}

A integridade de DNA foi avaliada utilizando-se a coloração com acridine orange, segundo o método de Thuwanut et al. (2008). Foi preparado um esfregaço em lâmina com $10 \mu \mathrm{L}$ de sêmen, o qual foi seco ao ar. O esfregaço foi fixado em solução de Carnoy (metanol: ácido acético, 3: $1 \mathrm{v} / \mathrm{v}$ ) preparada no momento do uso, durante 3 horas ou overnight. Então, as lâminas foram coradas com acridine orange $(10 \mathrm{~mL}$ da solução $10 \mathrm{mg} / \mathrm{mL}$ de acridine orange, $40 \mathrm{~mL}$ solução de ácido cítrico $0,1 \mathrm{M}$ e 2,5 $\mathrm{mL}$ solução $\mathrm{Na}_{2} \mathrm{HPO}_{4} \cdot 7 \mathrm{H}_{2} \mathrm{O} 0,3 \mathrm{M}$ - $\mathrm{pH} 2,5$, durante 5 minutos), lavadas em água destilada, recobertas por lamínula e observadas em microscópio de epifluorescência (490/530 nm de excitação/ filtro de barreira). Foram analisadas 200 células, sendo as que continham DNA íntegro (DNA nativo - dupla fita) foram coradas em verde fluorescente, enquanto os espermatozoides com DNA anormal (DNA desnaturado) foram corados em um espectro variando do amarelo-esverdeado ao vermelho.

\section{Integridade da membrana}

A integridade estrutural da membrana foi avaliada pela coloração com sondas fluorescentes, a qual foi realizada de acordo com a técnica descrita por Harrison e Vickers (1990) modificada. As soluções estoques de diacetato de 6-carboxifluoresceína $(9,2$ $\mathrm{mg}$ diacetato de 6-carboxifluoresceína em $20 \mathrm{~mL}$ dimetilsulfóxido (DMSO)), iodeto de propídeo (10 mg de iodeto de propídeo em $20 \mathrm{~mL}$ solução fisiológica), formaldeído (diluição de 1: 80 de formalina a $40 \%$ em solução fisiológica) e citrato de sódio a $3 \%$ (3,0 g de citrato de sódio em $100 \mathrm{~mL}$ de solução fisiológica) foram preparadas. Uma fração de $10 \mu \mathrm{l}$ de sêmen foi diluída em $40 \mu \mathrm{l}$ da solução trabalho ( $5 \mu \mathrm{l}$ da solução estoque de diacetato de 6-carboxifluoresceína, $20 \mu \mathrm{L}$ da solução estoque de iodeto de propídeo, $10 \mu \mathrm{l}$ solução estoque de formaldeído e $960 \mu \mathrm{l}$ de citrato de sódio a $3 \%$ ), preparada no momento do uso. Uma gota do material foi depositada em uma lâmina de vidro, recoberta por lamínula e analisada em microscópio de epifluorescência (Olympus, BX60, USA), em aumento de 1.000 X (imersão), com filtro WG. Foram contadas 200 células, sendo consideradas 
com a membrana íntegra aquelas coradas em verde e com a membrana lesada as coradas em vermelho ou vermelho e verde.

A integridade funcional da membrana foi avaliada pelo teste hiposmótico segundo a técnica descrita por Jeyendran et al. (1984), que consistiu em misturar $0,1 \mathrm{~mL}$ do sêmen com 0,9 $\mathrm{mL}$ da solução hiposmótica de $150 \mathrm{mOsmol}(7,35 \mathrm{~g}$ citrato de sódio. $2 \mathrm{H}_{2} \mathrm{O}, 13,51 \mathrm{~g}$ frutose em $1000 \mathrm{~mL}$ de água destilada). Uma solução isosmótica de $300 \mathrm{mOsmol}(14,7 \mathrm{~g}$ citrato de sódio. $2 \mathrm{H}_{2} \mathrm{O}, 27,02 \mathrm{~g}$ frutose em $1000 \mathrm{~mL}$ de água destilada) foi utilizada como controle. O material foi incubado a $37^{\circ} \mathrm{C}$, durante 5 minutos. Após o período de incubação, as amostras foram, suavemente, agitadas por movimentos de inversão e uma gota do material foi colocada em uma lâmina de vidro, recoberta por uma lamínula e a leitura realizada em microscópio de contraste de fase. Foram contadas 200 células espermáticas, em vários campos da lâmina, escolhidos aleatoriamente. $\mathrm{Na}$ solução hiposmótica foram considerados espermatozoides com integridade funcional da membrana, aqueles que apresentaram edema, evidenciado pelo enrolamento da cauda. A solução isosmótica serviu como controle para descartar os espermatozoides que já apresentavam cauda enrolada antes do teste. O resultado foi dado em porcentagem, sendo que o valor final foi obtido da quantidade de espermatozoides com a cauda enrolada, na solução hiposmótica, subtraída a quantidade de espermatozoides com a cauda enrolada na solução isosmótica.

\section{Viabilidade espermática}

A viabilidade espermática foi avaliada utilizando-se uma solução de eosina/nigrosina preparada $(5 \% \mathrm{p} / \mathrm{v}$ de nigrosina, $0,6 \% \mathrm{p} / \mathrm{v}$ de nigrosina e $3 \%$ de $\mathrm{p} / \mathrm{v}$ de citrato de sódio. $2 \mathrm{H}_{2} \mathrm{O}, \mathrm{pH} 7,0-$ quando necessário foi utilizado $0,1 \mathrm{M} \mathrm{NaH}_{2} \mathrm{PO}_{4}$ ou $0,1 \mathrm{M} \mathrm{Na}_{2} \mathrm{HPO}_{4}$ para ajustar o $\mathrm{pH}$ ) e filtrada, segundo Barth e Oko (1989). Um esfregaço foi confeccionado com uma alíquota de $5 \mu \mathrm{L}$ da solução e a mesma quantidade de sêmen foi colocada sobre uma lâmina. Após secar ao ar, a lâmina foi analisada, contandose 200 células em microscópio óptico (400X), sendo as coradas em rosa/preto consideradas com a membrana lesada.

\section{Atividade mitocondrial}

A atividade citoquímica das mitocôndrias foi avaliada pelo método descrito por Hrudka (1987) e Cavalcante et al. (2005). Amostras de sêmen foram incubadas em meio contendo diaminobenzidina (DAB) em fosfato de sódio $0,15 \mathrm{M}, \mathrm{pH} 7,2$, a uma concentração de $1 \mathrm{mg} / \mathrm{mL}$ e manuseado na ausência de luz. Uma alíquota de $10 \mu \mathrm{L}$ (in natura) e $250 \mu \mathrm{L}$ (pós-descongelação) de sêmen foi adicionada a $1 \mathrm{~mL}$ e $750 \mu \mathrm{L}$, respectivamente, do meio de incubação, homogeneizada em tubo aberto, colocada em banho-maria a $37^{\circ} \mathrm{C}$ durante 60 minutos, na ausência de luz. Para cada ensaio realizado, um controle negativo foi obtido da incubação de uma amostra de sêmen aquecida a $100^{\circ} \mathrm{C}$ por cinco minutos e adicionada ao meio de incubação, da mesma maneira que amostra teste. Após a incubação, esfregaços da amostra teste e controle foram preparados, fixados em formaldeído $10 \%$, durante 10 minutos, lavados e secos ao ar. Então, as lâminas foram avaliadas em microscópio de contraste de fase, num aumento de 1.000X. Foram contadas 200 células, classificadas em quatro categorias: categoria 1 (a maioria das mitocôndrias ativas, nas quais a bainha mitocondrial possuía a aparência de um cilindro compacto e proeminente); categoria 2 (bainha mitocondrial fragmentada, contendo segmentos ativos e inativos com predominância dos ativos); categoria
3 (menos da metade da bainha mitocondrial está ativa, com poucas mitocôndrias ativas dispersas); e categoria 4 (bainha mitocondrial completamente inativos). Cada categoria foi multiplicada por um fator de correção, sendo para categoria 1 , 1,0 ; categoria 2, 0,5; categoria $3,0,25$; e categoria 4 , zero. 0 índice de atividade citoquímica mitocondrial foi encontrado após a multiplicação do número de espermatozoides encontrados em cada categoria pelo seu fator de correção e a somatória dos valores de todas as classes.

\section{Diluição e congelamento do sêmen}

A partir da concentração espermática da amostra colhida, a quantidade de diluente foi calculada em $\mathrm{mL}$. O sêmen foi diluído em meio Botubov ${ }^{\circledR}$ - meio II (Botupharma, Botucatu, SP, Brasil), contendo aproximadamente $4 \%$ de glicerol, na solução final. Após a diluição, as amostras foram envasadas em palhetas francesas de $0,5 \mathrm{~mL}$, contendo $50 \times 10^{6}$ espermatozoides móveis/ palheta.

As palhetas foram acomodadas em uma grade de metal e refrigeradas a $4^{\circ} \mathrm{C}$, durante 4 horas. Após este período, a grade de metal, com as palhetas, foi transferida para uma caixa de isopor, contendo nitrogênio líquido e acomodada a $6 \mathrm{~cm}$ acima da superfície líquida, durante 20 minutos. Finalmente, as palhetas foram imersas no nitrogênio líquido e, posteriormente, armazenadas em botijão criogênico. As palhetas foram descongeladas a $37^{\circ} \mathrm{C}$ em banho-maria, durante 30 segundos e reavaliadas pelos mesmos testes, com exceção da concentração espermática.

\section{Análise estatística}

Todos os dados foram testados para normalidade pelo teste de Kolmogorov-Smirnov. As variáveis foram avaliadas pelo teste de Mann-Whitney (Rank Sum Test), comparando-se os dados obtidos de cada touro e entre os touros, antes e após a congelação do sêmen. O nível de significância considerado foi $p<0,05$.

\section{Resultados}

Os resultados de todas as amostras foram apresentados na Tabela 1.

Ao final do experimento, foram utilizados 35 pares de testículos/ epidídimos de touros provenientes do abatedouro comercial da região, porém apenas 10 foram considerados para o experimento. Os restantes foram descartados devido à ausência de células espermáticas ou foram utilizados para adaptação das técnicas propostas no estudo.

O número médio de espermatozoides recuperados da cauda do epidídimo variou entre 1,7 a $12,7 \times 10^{9}$ espermatozoides, com uma média e desvio-padrão de $5,2 \times 10^{9} \pm 3,8 \times 10^{9}$.

Em relação à motilidade e vigor espermático do sêmen fresco e após a descongelação verificou-se média e desvio-padrão de $74,0 \pm 7,0 \%$ e $3,6 \pm 0,7,30,0 \pm 8,2 \%$ e $1,3 \pm 0,5$, respectivamente. As médias da motilidade $(p<0,001)$ e vigor espermático $(p<0,001)$ do sêmen fresco foram superiores à do congelado.

$\mathrm{Na}$ avaliação da atividade citoquímica das mitocôndrias foi verificada uma quantidade maior de padrão um e dois para o sêmen fresco. O índice médio de atividade citoquímica foi calculado e notou-se uma redução $(p<0,001)$ após a descongelação $(99,3 \pm 6,6$ versus $40,0 \pm 6,3)$. Não foi observada 
correlação entre a motilidade espermática e o índice médio de atividade citoquímica mitocondrial, tanto no sêmen fresco como no congelado.

Com relação à integridade de membrana, houve uma redução $(p<0,001)$ após a descongelação.

Tabela 1: Média \pm desvio-padrão da análise do sêmen fresco e congelado, colhido do epidídimo de 10 touros

\begin{tabular}{lcc}
\hline \hline CARACTERÍSTICA AVALIADA & FRESCO & CONGELADO \\
\hline Volume $(\mathrm{mL})$ & $6,3 \pm 2,1$ & -- \\
Concentração espermática no ejaculado $\left(\times 10^{9}\right)$ & $5,2 \pm 3,8$ & -- \\
Motilidade (\%) & $74 \pm 7,0^{\mathrm{a}}$ & $30,0 \pm 8,2^{\mathrm{b}}$ \\
Vigor (0 a 5) & $3,6 \pm 0,7$ & $1,3 \pm 0,5$ \\
Integridade DNA (\%) & $99,2 \pm 0,9$ & $98,2 \pm 1,8$ \\
Índice de atividade citoquímica mitocondrial & $99,3 \pm 6,6^{\mathrm{a}}$ & $40,0 \pm 6,3^{\mathrm{b}}$ \\
Eosina (\%) & $70,3 \pm 9,5$ & $66,5 \pm 8,8$ \\
Fluoresceína e iodeto de propídio (\%) & $95,9 \pm 3,1^{\mathrm{a}}$ & $75,7 \pm 5,9^{\mathrm{b}}$ \\
Hiposmótico (\%) & $77,4 \pm 10,2$ & $72,9 \pm 10,4$ \\
Normais (\%) & $66,8 \pm 10,7$ & $62,7 \pm 8,5$ \\
Defeitos maiores (\%) & $7,7 \pm 2,8$ & $8,8 \pm 3,1$ \\
Defeitos menores (\%) & $25,5 \pm 9,4$ & $28,6 \pm 7,8$ \\
\hline \hline
\end{tabular}

Letras diferentes na mesma linha indicam diferença significativa $(p<0,05)$.

\section{Discussão}

Baseado nos resultados do presente estudo, foi observado que o número médio de espermatozoides recuperados da cauda do epidídimo está de acordo com a média esperada para o sêmen ejaculado de touros de 0,4 a $20 \times 10^{9}$ espermatozoides (Gonçalves et al., 2008). Os valores obtidos poderiam ser maiores, pois o estudo foi realizado com animais do rebanho comercial, destinados ao abate, muitas vezes com testículos pequenos, e por não serem reprodutores.

Na técnica de colheita do sêmen por fluxo retrógrado empregada neste estudo, a média encontrada para concentração espermática foi superior a resultados de outros autores, sendo de $1,7 \times 10^{9}$ espermatozoides (variação de $0,26 \times 10^{9}$ a 4,2×109), colhidos por método distinto, a fragmentação e lavagem da cauda do epidídimo (Castro et al., 2009), o que aumenta muito o potencial de doses de sêmen a serem produzidas. Além disso, a técnica de fluxo retrógrado permitiu a colheita de amostras sem contaminação com sangue, sendo mais eficiente e parecendo ser o método mais recomendado para esta espécie (MartinezPastor et al., 2006).

A porcentagem de morfologia espermática encontrou-se abaixo do recomendado para a espécie (CBRA, 1998) e a gota citoplasmática distal foi o principal defeito nas amostras avaliadas, concordando com outros estudos (Amann et al.,
1974; Silva et al., 2003, Tajik et al., 2007). Apesar disto, a gota citoplasmática está presente nos espermatozoides da cauda do epidídimo e é perdida durante a ejaculação (Garbers et al., 1970; Cooper e Yeung, 2003), sendo uma alteração esperada nestas amostras.

A motilidade e vigor espemáticos do sêmen fresco e descongelado foram semelhantes aos encontrados para o sêmen ejaculado (CBRA, 1998; Severo, 2009), confirmando a viabilidade do método para aplicação em biotécnicas da reprodução.

Outras alterações foram encontradas após a congelação, especialmente com avaliação citoquímica mitocondrial, que reduziu após a descongelação. Este achado é explicado pela perda de energia nas células espermáticas após a descongelação, sendo um teste indicador da quantidade de adenosina trifosfato (ATP), a qual está relacionada com o número de espermatozoides móveis e a viabilidade espermática (Lindermann e Kanous, 1989; Tesarik et al., 1993; Januskauskas e Zilinskas, 2002).

De acordo com um questionário respondido pelas maiores centrais de inseminação do Brasil, a média da concentração espermática por palheta é de 13,73 milhões de espermatozoides (Crespilho et al., 2009). Assim, neste estudo, poderia ser produzido um total de 925 doses de sêmen, valor que pode variar em função do número de células espermáticas recuperadas, garantindo doses suficientes para a preservação do material genético de um touro. Isso torna a técnica muito rentável, pois é de fácil execução e baixo custo. Além disso, após a morte do reprodutor, o sêmen tende a se valorizar, havendo casos em que antes da morte o sêmen é comercializado por 20 a 30 reais e após a morte chega a mil reais a dose (Pontes, 2011).

O sêmen colhido do epidídimo de touros post-mortem tem maior valor no mercado e grande potencial para ser utilizado na fecundação in vitro (FIV). O Brasil é líder mundial dessa biotecnologia, realizando mais de 300 mil transferências de embriões por ano (Cardoso, 2012). Estudos têm comprovado a fertilidade e a utilização desta metodologia empregada no presente estudo. Martins et al. (2007) avaliaram a fertilidade do sêmen congelado obtido do epidídimo de touros após a morte na produção de embriões de FIV. Ademais, a fertilidade do sêmen congelado obtido do epidídimo na inseminação artificial foi comprovada por Barker em 1954 (Barker, 1954), e apesar da técnica de congelação e os meios diluentes utilizados serem diferentes dos atuais, a taxa de prenhez foi, em média, $63 \%$, não havendo diferenças na fertilidade entre o sêmen ejaculado e do epidídimo.

Com base nos resultados e nas condições em que foi realizado o estudo, conclui-se que a técnica de fluxo retrógrado é rápida e eficiente para a colheita de espermatozoides da cauda do epidídimo, com recuperação de alta concentração de células espermáticas. Tal técnica permitiu a colheita de células viáveis e que após a congelação poderiam ser utilizadas para inseminação artificial, sendo mantidas características semelhantes ao sêmen ejaculado. 
Além de ser uma técnica factível, contribuindo para a preservação de material genético de reprodutores superiores (principalmente animais jovens, que poderiam contribuir muito com o progresso genético e morrem precocemente), é economicamente viável, pois o valor de venda das doses do sêmen tende a se valorizar após a morte.

\section{Agradecimentos}

À FAPESP (Fundação de Amparo à Pesquisa do Estado de São Paulo) pelo auxílio concedido.

\section{Referências}

AMANN, R.P.; GRIEL Jr., L.C. Fertility of bovine spermatozoa from rete testis, cauda epididymidis, and ejaculated sperm. Journal of Dairy Science, v. 57, p. 212-9, 1974.

ASBIA Associação Brasileira de Inseminação Artificial. Index ASBIA. 2012 [acesso em 26 mar. 2012]. Disponível em: www. asbia.org.br/novo/upload/mercado/relatorio2011.pdf.

BARKER, C.A.V. Low temperature preservation of bovine epididymal spermatozoa. Canadian Journal of Comparative Medicine, v. 13, p. 390-393, 1954.

BARTH, A.D.; OKO, R.J. Abnormal morphology of bovine spermatozoa. Ames: lowa State University Press, 1989, 285p.

BEDFORD, J.M. The status and the state of the human epididymis. Human Reproduction, v. 9, p. 2187-2199, 1994.

BRUEMMER, J.E.; REGER, H.; ZIBINSKI, G.; SQUIRES, E.L. Effect of storage at $5^{\circ} \mathrm{C}$ on the motility and cryopreservation of stallion epididymal spermatozoa. Theriogenology, v. 58, p. 405-407, 2002.

CARDOSO, D. As novas tecnologias, passo a passo. Revista DBO, n. 377, ano 31, p. 36-46, 2012.

CASTRO, J.B.; CASAS, V.F.; SOUZA, F.F. Viabilidade dos espermatozoides colhidos do epidídimo de touros 24 horas postmortem. In: CONGRESSO BRASILEIRO DE REPRODUÇÃO ANIMAL, 2009, Anais... Belo Horizonte: CBRA, 2009.

CAVALCANTE, T.V.; ESPER, C.R.; FERREIRA, J.L.; DIAS, F.E.F.; AZEVEDO, H.C.; CORDEIRO, M.F.; SOUZA, J.A.T. Avaliação da atividade mitocondrial em espermatozoides pós-colheita e pósdescongelação de caprinos das raças Boer e Alpina no outono e primavera. Archives of Veterinary Science, v. 10, p. 89-93, 2005.

CBRA. Manual prático para exame andrológico e avaliação de sêmen animal. 2. ed., Belo Horizonte: Editora do Colégio Brasileiro de Reprodução Animal, 1998, p. 49.

COOPER, T.G.; YEUNG, C. Acquisition of volume regulatory response of sperm upon maturation in the epididymis and the role of the cytoplasmic droplet. Microscopy Research and Technique, v. 61, n. 1, p. 28-38, 2003.

CRESPILHO, A.M.; PAPA, F.O.; MARTINS JUNIOR, A.; DELLAQUA JR., J.A. Evaluation of frozen bovine semen: How do semen collection and processing centers evaluate the commercialized samples? Veterinária e Zootecnia (UNESP), v. 16, p. 335-342, 2009. GARBERS, D.L.; WAKABAYASHI, T.; REED, P.W. Enzyme profile of the cytoplasmic droplet from bovine epididymal spermatozoa. Biology of Reproduction, v. 3, n. 3, p. 327-337, 1970.

GARDE, J.; AGUADO, M.; PEREZ, S.; GARRIDO, D.; PEREZGUZMAN, M.; MONTORO, V. Physiological characteristics of epididymal spermatozoa from postmortem rams. Theriogenology, v. 41, n. 1, p. 203, 1994.

GONÇALVES, P. B. D.; FIGUEIREDO, J. R.; FREITAS, V. J. Biotécnicas aplicadas à reprodução animal. 2ed. São Paulo: Editora Roca, 408 p. 2008.

HARRISON, R.A.P.; VICKERS, S.E. Use of fluorescent probes to assess membrane integrity in mammalian spermatozoa. Journal of Reproduction Fertility, v. 88, p. 343-352, 1990.

HINTON, B.T.; PALLADINO, M.A.; RUDOLPH, D.; LABUS, J.C. The epididymis as protector of maturing spermatozoa. Reproduction Fertility and Development, v. 7, p. 731-745, 1995.
HRUDKA, F. Cytochemical and ultracytochemical demonstratation of cytochrome $\mathrm{C}$ oxidase in spermatozoa and dynamics of its changes accompanying ageing or induced by stress. International Journal of Andrology, v. 19, p. 809-828, 1987.

JANUSKAUSKAS, A.; ZILINSKAS, H. Bull semen evaluation post-thaw and relation of semen characteristics to bull's fertility. Veterinarija ir Zootechnika, v. 17, n. 39, p. 1-8, 2002.

JEYENDRAN, R.S.; VAN DER VEN, H.H.; PEREZ-PELAEZ, M.; CRABO, B.G.; ZANEVELD, L.J.D. Development of an assay to assess the functional integrity of the human sperm membrane and its relationship to other semen characteristics. Journal Reproduction and Fertility, v. 47, p. 219-228, 1984.

LINDEMANN, C. B.; KANOUS, K. S. Regulation of mammalian sperm motility. Archives of Andrology, v. 23, p. 1-22, 1989.

MARTINEZ-PASTOR, F.; MACIAS V.G,; ALVAREZ M.; CHAMORRO C.; HERRAEZ P.; PAZ P.; et al. Comparison of two methods for obtaining spermatozoa from the cauda epididymis of Iberian red deer. Theriogenology. v. 65, p. 471-485, 2006.

MARTINS, C.F.; RUMPF R.; PEREIRA, D.C.; DODE, M.N. Cryopreservation of epididymal bovine spermatozoa from dead animals and its uses in vitro embryo production. Animal Reproduction Science, v. 101, p. 326-331, 2007.

PAPA, F.O., ALVARENGA, M.A., BICUDO, S.D., LOPES, M.D., RAMIRES, P.R.N. Coloração espermática segundo Karras modificado pelo emprego do Barbatimão (Sthyphnodendrum barbatiman). In: CONGRESSO DE BIOLOGIA CELULAR, 86. 1986. Anais... Rio de Janeiro, 1986.

PONTES, A. Fábrica de touros. Revista Dinheiro Rural, n. 79, p. 58-64, 2011.

SEVERO, N. C. Influência da qualidade do sêmen bovino congelado sobre a fertilidade. A Hora Veterinária, v. 28, n. 167, p. 36-39, 2009.

TAJIK, P.; ARMAN, A.; TAKTAZ, T. Bovine epididymal sperm morphology obtained from caput, corpus and cauda epididymides. Pakistan Journal of Biological Sciences, v. 10, n. 21, p. 3936-3939, 2007.

SILVA, A.E.D.F.; DIAS, A.L.; UNANIAN, M.M.; FREITAS, A.R.; BLOCH, C.J. Conteúdo de peptídeos e avaliação morfofisiológica dos espermatozóides do epidídimo e ejaculado de bovinos. Revista Brasileira de Zootecnia, v. 32, p. 1890-1900, 2003.

TESARIK, J.; MENDOZA, C.; CARRERAS, A. Fast acrosome reaction measure a highly sensitive method for evaluating stimulusinduced acrosome reaction. Fertility and Sterility, v. 53, p. 424-430, 1993.

THUWANUT, P.; CHATDARONG, K.; TECHAKUMPHU, M.; AXNER, E. The effect of antioxidants on motility, viability, acrosome integrity and DNA integrity of frozen-thawed epididymal cat spermatozoa. Theriogenology, v. 70, p. 233-240, 2008.

YAGINAMACHI, R. Mammalian fertilization. In: Knobil, E.; NEILL, J. The phisiology of reproduction. New York: Ed. Raven Press, p. 135-185, 1994.

YANG, X.; JIANG, S.; FOOTE, R.H. Bovine oocyte development following different oocyte maturation and sperm capacitation procedures. Molecular Reproduction and Development, v. 34, p. 94-100, 1993 